\title{
Occurrence of Fungicide Resistance in Botrytis cinerea from Greenhouse Tomato in Hubei Province, China
}

F. Fan, Key Lab of Horticultural Plant Biology, Ministry of Education, and College of Plant Science and Technology; N. Li and G. Q. Li, College of Plant Science and Technology and the Key Lab of Crop Disease Monitoring \& Safety Control in Hubei Province; and C. X. Luo, Key Lab of Horticultural Plant Biology, Ministry of Education, and College of Plant Science and Technology, Huazhong Agricultural University, Wuhan 430070, China

\begin{abstract}
Fan, F., Li, N., Li, G. Q., and Luo, C. X. 2016. Occurrence of fungicide resistance in Botrytis cinerea from greenhouse tomato in Hubei Province, China. Plant Dis. 100:2414-2421.

During the early summer of 2012 and 2013, samples of gray mold were collected from greenhouse tomato at eight locations in Hubei Province, and 221 isolates of Botrytis cinerea were obtained and evaluated for the sensitivity to fungicides carbendazim, diethofencarb, boscalid, fludioxonil, and cyprodinil. Results showed that isolates with resistance to carbendazim and cyprodinil were widespread, whereas isolates with resistance to carbendazim and diethofencarb were found at only two locations. No isolates with resistance to boscalid or fludioxonil were detected. Altogether, four resistant phenotypes were determined (i.e., $\operatorname{Car}^{\mathrm{R}} \mathrm{Die}^{\mathrm{S}} \mathrm{Cyp}{ }^{\mathrm{s}}$, $\operatorname{Car}^{R} \operatorname{Die}^{R} \operatorname{Cyp}^{\mathrm{S}}, \operatorname{Car}^{\mathrm{R}} \mathrm{Die}^{\mathrm{S}} \mathrm{Cyp}^{\mathrm{R}}$, and $\mathrm{Car}^{\mathrm{R}} \mathrm{Die}^{\mathrm{R}} \mathrm{Cyp}^{\mathrm{R}}$ ). Among them, $\mathrm{Car}^{\mathrm{R}} \mathrm{Die}^{\mathrm{S}} \mathrm{Cyp}{ }^{\mathrm{S}}$ and $\mathrm{Car}^{\mathrm{R}} \mathrm{Die}^{\mathrm{S}} \mathrm{Cyp}^{\mathrm{R}}$ were widely distributed, and there was a dominant resistant phenotype at each location. Interestingly, isolates resistant only to cyprodinil were not obtained because the resistance to cyprodinil was always associated with the resistance to carbendazim, demonstrating that a phenotype of multiple fungicide resistance of $B$. cinerea was more likely to have evolved from previously resistant subpopulations. Stability of resistance to carbendazim, diethofencarb, and cyprodinil was

assessed, and the resistance was stable. Fitness tests showed that, as a group, the carbendazim-resistant isolates were not significantly different from sensitive isolates. However, the mycelial growth and virulence of the carbendazim, diethofencarb, and cyprodinil triple-resistant group were significantly lower than the sensitive group, indicating that the tripleresistant isolates suffered from the disability of colonizing the hosts. It should be noted that there was no significant difference for other fitness components (e.g., sporulation or osmotic sensitivity to $\mathrm{NaCl}$ ), suggesting that the triple-resistant isolates were still competitive in these traits. To investigate the mechanisms of resistance to carbendazim and diethofencarb, partial $\beta$-tubulin genes of 10 carbendazim-resistant isolates and 5 isolates resistant to carbendazim and diethofencarb were sequenced, and all 10 carbendazim-resistant isolates harbored the mutation E198V or E198A. For the 5 isolates resistant to carbendazim and diethofencarb, all of them possessed the mutation E198K, and no other mutations were detected. The location-specific resistance profiles found in this study are crucial in designing proper gray mold management strategies in these areas.
\end{abstract}

Gray mold, caused by Botrytis cinerea Pers. (teleomorph: Botryotinia fuckeliana), is one of the most economically important diseases of greenhouse-grown vegetables worldwide. Management of this disease has largely depended on chemical control achieved by several classes of fungicides, especially the site-specific fungicides (Bardas et al. 2008; Sun et al. 2010). Benzimidazoles (MBC), N-phenylcarbamates (NPC), quinone outside inhibitors, succinate dehydrogenase inhibitors (SDHI), and anilinopyrimidines (AP) are several common classes of fungicides used in China. However, Botrytis cinerea is a high-risk pathogen for the development of fungicide resistance, and resistance to fungicides is a concern in vegetable production (Brent et al. 1998).

Carbendazim, an MBC fungicide, can inhibit germ-tube elongation and mycelial growth by binding to $\beta$-tubulin, preventing microtubule assembly (Leroux et al. 1999). Resistance to carbendazim in B. cinerea developed soon after its introduction in the 1970s (Bolton 1976; Triphati and Schlosser 1982). The resistance was conferred by mutations of a $\beta$-tubulin gene (TUB2) at codon 198, which altered from glutamic acid to alanine (E198A), valine (E198V), or lysine (E198K) (Leroux et al. 2002; Malandrakis et al. 2011; Yarden and Katan 1993)

Diethofencarb, an NPC fungicide, is also an antimicrotubule fungicide. This compound was not effective against wild-type isolates but frequently showed negative cross resistance with MBC fungicides. Therefore, a mixture of carbendazim and diethofencarb was

Corresponding author: C. X. Luo; E-mail: cxluo@mail.hzau.edu.cn

Accepted for publication 5 August 2016.

http://dx.doi.org/10.1094/PDIS-03-16-0395-RE

(C) 2016 The American Phytopathological Society released to control $B$. cinerea and has been applied since the late 1990s in China (Leroux et al. 1999; Zhang et al. 2009b; Ziogas and Girgis 1993). Due to the intense application of the mixture, isolates showing dual resistance to carbendazim and diethofencarb were widely detected in different countries (Elad et al. 1992; Sun et al. 2010). This dual resistance was generally related to the E198K or F200Y mutation of the TUB2 gene (Malandrakis et al. 2011; Yarden and Katan 1993).

Boscalid and cyprodinil were registered to control gray mold in recent years. Boscalid belongs to the SDHI fungicides that prevent mitochondrial respiration by inhibiting the activity of mitochondrial respiratory complex II, also known as succinate dehydrogenase (Kim and Xiao 2011). This novel mode of action makes it an excellent candidate for management of fungicide resistance in $B$. cinerea (Zhang et al. 2007). On the other hand, due to the site-specific mode of action, the fungus could develop resistance easily based on very few genetic modifications (Bardas et al. 2010; Fernández-Ortuño et al 2012; Lalève et al. 2014; Weber 2011). Mutations in subunit SdhB leading to the substitution from proline to leucine, phenylalanine, or threonine at codon 225 (P225 L, P225F, or P225T); and the replacement from histidine to tyrosine, arginine, or leucine at codon 272 (H272Y, H272R, or H272L) or from asparagine to isoleucine at codon 230 (N230I) were frequently detected in laboratory mutants or field isolates and have been confirmed as responsible for the resistance to SDHI in B. cinerea (Fernández-Ortuño et al. 2012; Lalève et al. 2014). In addition, the substitution from histidine to arginine at codon 132 (H132R) in subunit SdhD was detected in field isolates with resistance to boscalid (Leroux et al. 2010).

Cyprodinil is one of the AP fungicides. Even though a significant amount of research has been conducted, the primary mode of action of this fungicide has not yet been clarified (Fritz et al. 1997; Masner et al. 1994; Milling and Richardson 1995). It has been suggested that AP fungicides inhibit the biosynthesis of methionine and other amino 
acids, and prevent the secretion of hydrolytic enzymes involved in the infection process (Fernández-Ortuño et al. 2013b; Masner et al. 1994). B. cinerea resistant to AP from fields has been reported in many studies (Bardas et al. 2010; Li et al. 2014a; Weber 2011; Zhang et al. 2009a), indicating the high risk for the development of resistance to this class of fungicides.

Fludioxonil belongs to the phenylpyrrole (PP) fungicides, whose primary mode of action still remains unknown as well. It has been hypothesized that PP fungicides inhibit the transport-associated phosphorylation of glucose and interfere with the osmotic signal transduction pathway by inhibiting a protein kinase (PK-III), resulting in an abnormal accumulation of glycerol (Fernández-Ortuño et al. 2013b; Jespers and De Waard 1995; Pillonel and Meyer 1997). Although the laboratory mutants resistant to PP can easily be generated and show cross-resistance to dicarboximide fungicides (Leroux et al. 1999; Vermeulen et al. 2001), the resistant isolates from fields were not detected until recently in France, Germany, and several states in the United States (Fernández-Ortuño et al. 2013a, 2014b,c; Kretschmer et al. 2009). The overexpression of ATP-binding cassette transporter gene $B$ catr $B$ and major facilitator superfamily transporter gene $M f_{s} M 2$ and mutations in the transcription factor $\mathrm{Mrrl}$ are related to the resistance to PP in B. cinerea (Kretschmer et al. 2009; Li et al. 2014b; Vermeulen et al. 2001).

Hubei is an important province for vegetable growth, where 36.7 million tons of vegetables were produced in 2014 (vegetable database from Department of Crop Production, Ministry of Agriculture, China). Gray mold is one of the most devastating diseases on vegetables, especially on greenhouse vegetables in Hubei. Even though fungicides are routinely applied to control this disease, efficacy of some fungicides has decreased in recent years. The objectives of this study were to (i) determine the resistance profiles of $B$. cinerea from greenhouses at several locations in Hubei, China to carbendazim, diethofencarb, boscalid, fludioxonil, and cyprodinil; (ii) characterize the resistant isolates through evaluating the fitness in vitro and in vivo; and (iii) detect point mutations in the target genes. This information is not only useful for designing proper management strategies but also crucial for establishing the molecular detection methods for resistance in the future.

\section{Materials and Methods}

Fungicides. Technical-grade carbendazim (92\% active ingredient [a.i.]; Hubei Jianyuan Chemical Co., Ltd.), diethofencarb (95.4\% a.i.; Jiangsu Lanfeng Biochemical Co., Ltd.), boscalid (97\% a.i.; Hubei Kangbaotai Fine-Chemicals Co., Ltd.), fludioxonil (97\% a.i.; Hubei Jianyuan Chemical Co., Ltd.), and cyprodinil (98.1\% a.i.; Hubei Kangbaotai Fine-Chemicals Co., Ltd.) were used in this study. To make stock solutions, diethofencarb, boscalid, fludioxonil, and cyprodinil were dissolved in acetone at the concentrations of 5,000, 10,000, 200 , and 2,000 $\mu \mathrm{g}$ a.i./ml, respectively, while carbendazim was dissolved in lactic acid at a concentration of 10,000 $\mu \mathrm{g}$ a.i./ml. Stock solutions were stored at $4^{\circ} \mathrm{C}$ in darkness before use. To evaluate the control efficacy against resistant isolates, commercial products of different fungicides were applied: Guoguang (50\% WP of carbendazim; Sichuang Guoguang Agrochemical Co., Ltd.), Gold Wanmeiling (25\% WP of carbendazim and 25\% diethofencarb; Jiangsu Lanfeng Biochemical Co., Ltd.), and Rongya (50\% WPG of cyprodinil; Jixi Nonghua Biotechnology Co., Ltd.).

Collection of $\boldsymbol{B}$. cinerea isolates. In total, 221 single-spore isolates of $B$. cinerea were isolated between 2012 and 2013 from diseased fruit or leaves of tomato from various greenhouses at different locations of Hubei (Table 1). The five classes of fungicides (MBC, NPC, SDHI, $\mathrm{AP}$, and $\mathrm{PP}$ ) with different modes of action were frequently sprayed during the growing season in some of these greenhouses. For longterm storage, isolates were maintained on dried filter paper as described before (Luo et al. 2002). Briefly, the isolates were allowed to grow on filter paper disks placed on potato dextrose agar (PDA; $200 \mathrm{ml}$ of juice from $200 \mathrm{~g}$ of potato, $20 \mathrm{~g}$ of dextrose, and $15 \mathrm{~g}$ of agar per liter) and, after 5 days, disks with mycelium were removed, desiccated, and stored at $-20^{\circ} \mathrm{C}$. All 221 isolates were identified to the species level by their morphological characteristics and molecular methods, as described previously (Fan et al. 2015). In brief, all isolates were identified as $B$. cinerea by polymerase chain reaction (PCR)-based assay, in which specific primer pair Bc-f/Bc-r (CAG GAA ACA CTT TTG GGG ATA/ GAG GGA CAA GAA AAT CGA CTA A) was used to amplify the B. cinerea-specific 327-bp fragment.

Sensitivity assay of $B$. cinerea to carbendazim, diethofencarb, boscalid, fludioxonil, and cyprodinil in vitro. Discriminatory doses for each fungicide used in this study were determined previously (Fernández-Ortuño et al. 2014a; Sun et al. 2010). To assess sensitivity to carbendazim, diethofencarb and fludioxonil, mycelial growth of the isolates was measured on $1 \%$ malt extract agar amended with carbendazim at $10 \mu \mathrm{g} / \mathrm{ml}$, diethofencarb at $5 \mu \mathrm{g} / \mathrm{ml}$, and fludioxonil at $0.4 \mu \mathrm{g} / \mathrm{ml}$. To assess sensitivity to boscalid and cyprodinil, mycelial growth was measured on $1 \%$ yeast bacto acetate agar amended with boscalid at $75 \mu \mathrm{g} / \mathrm{ml}$ and on CzapeK-Dox agar medium (CzA) amended with cyprodinil at $4 \mu \mathrm{g} / \mathrm{ml}$, respectively. Mycelial plugs ( $5 \mathrm{~mm}$ in diameter) were removed from the periphery of a 3-day-old colony of each isolate using a cork borer and placed upside down onto fungicide-amended media. Isolates were incubated for 3 days at $22^{\circ} \mathrm{C}$ and then colony diameter was measured. For diethofencarb, boscalid, fludioxonil, and cyprodinil, isolates were regarded as resistant if the mycelial growth inhibition on fungicide-amended media was less than $80 \%$ compared with the growth on fungicide-free media. For carbendazim, isolates were regarded as resistant if they could grow on $10-\mu \mathrm{g} / \mathrm{ml}$ carbendazim-amended medium. The experiment had three replicates and was conducted once.

Evaluation of stability of resistance in vitro. To evaluate the stability of resistance in vitro, an adjusted method based on a previous study was adopted (Kim and Xiao 2011). In general, three isolates resistant to carbendazim and six isolates resistant to carbendazim, diethofencarb, and cyprodinil were arbitrarily selected and cultured on fungicide-free PDA plates. The cultures were renewed every 4 days by transferring active mycelial plugs to fresh fungicide-free PDA plates. The plates were incubated at $22^{\circ} \mathrm{C}$ in the dark. For each isolate, three replicate plates were tested and, in total, the isolates were cultured for 10 generations. The sensitivity to carbendazim, diethofencarb, or cyprodinil was determined before the first and after the last transfer by the method described as follows. Mycelial plugs ( $5 \mathrm{~mm}$ in diameter) were cut from the margin of 3-day-old colonies with a sterile cork borer and transferred upside down to the center of media plates amended with a series of fungicide doses. To test the sensitivity to carbendazim and diethofencarb, PDA plates amended with either fungicide at $0,0.3,1$, 3, 10, 30, and $100 \mu \mathrm{g}$ a.i./ml and, for cyprodinil, CzA plates amended with fungicide at $0,0.3,1,3,10,30$, and $100 \mu \mathrm{g}$ a.i./ml were used. After 3 days of incubation at $22^{\circ} \mathrm{C}$, the average colony diameter of three replicates was determined by measuring each colony in two perpendicular directions. The percentage of mycelial growth inhibition was calculated using the formula percent inhibition $=(1-\mathrm{A} / \mathrm{N}) \times 100 \%$, where $\mathrm{A}$ is the

Table 1. Frequency of resistance in Botrytis cinerea isolates collected from greenhouses of tomato in Hubei Province during 2012 and 2013

\begin{tabular}{lcccccc}
\hline & & \multicolumn{5}{c}{ Frequency of resistant isolates $(\%)^{\mathbf{x}}$} \\
\cline { 3 - 7 } Location $^{\mathbf{y}}$ & $\boldsymbol{N}^{\mathbf{z}}$ & Car & Die & Bos & Flu & Cyp \\
\hline HG & 31 & 6.45 & 0 & 0 & 0 & 0 \\
JM & 47 & 93.62 & 84.09 & 0 & 0 & 89.36 \\
JZ & 27 & 70.37 & 0 & 0 & 0 & 3.70 \\
QJ & 20 & 55.00 & 63.64 & 0 & 0 & 45.00 \\
SY & 11 & 72.73 & 0 & 0 & 0 & 9.09 \\
XT & 21 & 47.62 & 0 & 0 & 0 & 0 \\
XY & 26 & 15.38 & 0 & 0 & 0 & 3.85 \\
XG & 38 & 28.95 & 0 & 0 & 0 & 26.32 \\
Total & 221 & 49.32 & 40.37 & 0 & 0 & 28.96 \\
\hline Car & & &
\end{tabular}

${ }^{\mathrm{x}} \mathrm{Car}=$ carbendazim, Die $=$ diethofencarb, Bos = boscalid, Flu = fludioxonil, and Cyp = cyprodinil; diethofencarb resistance was counted when isolates were resistant to carbendazim.

${ }^{\mathrm{y}} \mathrm{HG}=$ Huanggang, $\mathrm{JM}=$ Jingmen, $\mathrm{JZ}=$ Jingzhou, QJ = Qianjiang, $\mathrm{SY}=$ Shiyan, $\mathrm{XT}=$ Xiantao, $\mathrm{XY}=\mathrm{Xiangyang}$, and $\mathrm{XG}=\mathrm{Xiaogan}$.

${ }^{\mathrm{z}}$ Number of isolates. 
mean colony diameter of colonies grown on treated PDA plates and $\mathrm{N}$ is that on nontreated PDA plates. The concentration at which mycelial growth is inhibited by $50 \%\left(\mathrm{EC}_{50}\right)$ value was assessed by regressing percentage of mycelial growth inhibitions against the $\log _{10}$ of fungicide concentrations. The experiment was conducted twice.

Measurement of fungal mycelial growth and sporulation in vitro. Mycelia growth in vitro of six sensitive isolates, three isolates resistant to carbendazim, and six isolates resistant to carbendazim, diethofencarb, and cyprodinil was measured on fungicide-free PDA plates. Mycelia plugs (5 $\mathrm{mm}$ in diameter) were cut from the margin of 3-day-old colonies of each isolate and transferred upside down to the center of PDA plates. For each isolate, one set of four plates was incubated at $22^{\circ} \mathrm{C}$ for 3 days in the dark. The colony diameters were then measured at two perpendicular directions. The experiment was conducted twice.

To determine sporulation of each isolate, mycelia plugs were cut from the periphery of colonies on 3-day-old PDA and placed upside down at the center of PDA plates. The plates were incubated at $22^{\circ} \mathrm{C}$ in the dark for 3 weeks. To collect spores, each plate was flooded with $3 \mathrm{ml}$ of sterile water and then the conidial suspension was filtered through one layer of lens-cleaning paper. The concentration of conidia was estimated with a hemacytometer and expressed as the number of conidia per square centimeter of the PDA culture. Three droplets of the suspension per replicate and four replicates for each isolate were counted. The experiment was conducted twice.

Determination of osmotic sensitivity. To test the osmotic sensitivity, 5-mm mycelia plugs grown on 3-day-old PDA plates were taken from the edge of actively growing colonies of each isolate and placed upside down at the center of PDA plates amended with $8 \% \mathrm{NaCl}$ or PDA plates as controls. After 3 days of incubation at $22^{\circ} \mathrm{C}$ in the dark, colony diameters were measured in two perpendicular directions. The percentage of mycelial growth inhibition was calculated by a formula similar to that described in the sensitivity test. For each isolate, four replicate plates were used and the experiment was conducted twice.

Evaluation of fungal virulence and sporulation in vivo. The virulence of the 15 isolates exhibiting different phenotypes was evaluated on tomato fruit. Tomato fruit of unknown cultivars of similar size and commercial maturity were first washed with dish detergent, followed by a rinse with tap water; then, the fruit were soaked in $\mathrm{NaClO}$ at $600 \mathrm{mg} / \mathrm{liter}$ for $10 \mathrm{~min}$. After that, each fruit was rinsed with tap water twice and allowed to air dry. For inoculation, three 5-by-2-mm (diameter by depth) plugs were removed from each fruit at three equidistant locations with a cork borer ( $5 \mathrm{~mm}$ in diameter). A 5-by-2-mm plug taken from the periphery of 3-day-old colony grown on PDA was inserted upside down into each of the prepared tomato holes. After inoculation, tomato fruit were placed in plastic boxes with tissue soaked with sterile water at the bottom. The plastic boxes were covered with cling film to keep the relative humidity around $100 \%$ and maintained at $22^{\circ} \mathrm{C}$ for 3 days. Lesion diameter was then measured. The experiment was conducted twice, with three replicates per fruit and three fruit per treatment.

After lesion diameters were measured, each tomato fruit was put back for another 14 days to facilitate the spore production. To collect the conidia, all decayed tissues of each fruit were cut off with a scalpel, placed in $15 \mathrm{ml}$ of water in a plastic bowl, and vortexed to dislodge the conidia. The conidia suspension was then filtered through one layer of lenscleaning paper. Three droplets of the conidial suspension per replicate and three replicates were counted to determine spore density in the conidial suspension with a hemacytometer. The sporulation was expressed as number of conidia per square centimeter of diseased tomato surface.

Evaluation of control efficacy of fungicides to resistant isolates in vivo. To test fungicide efficacy, three sensitive isolates and three triple-resistant isolates were selected. The tomato fruit was prepared as described above. Before inoculation, the fruit was sprayed with the highest recommended rates of Guoguang, Gold Wanmeiling, or Rongya, all at $1.7 \mathrm{~g} /$ liter. Untreated fruit was used as the control. After the surface of the fruit was air dried, they were inoculated as described above and incubated at $22^{\circ} \mathrm{C}$. Lesion diameters were measured after 3 days. Disease incidence was expressed as the percentage of wounds infected compared with the total number of wounds inoculated, and control efficacy was expressed as the percentage of the mean lesion diameter of the control minus the mean diameter of the treatment divided by the mean diameter of the control. This experiment was performed twice, with three replicates per fruit and three fruit per treatment.

Sequencing of the TUB2 gene from carbendazim-resistant isolates and isolates resistant to carbendazim and diethofencarb. Ten carbendazim-resistant isolates and five isolates resistant to carbendazim and diethofencarb were randomly selected. Two carbendazimsensitive isolates were selected as control. Isolates of $B$. cinerea were cultured on PDA plates with cellophane at $22^{\circ} \mathrm{C}$ for 3 days, and mycelia were collected using a toothpick. Genomic DNA was extracted and purified according to the method described previously (Chi et al. 2009). The partial TUB2 gene was amplified by PCR with primer pair TubA F/R (GAT CTC CAA CTT GAG CGT A/TGG AAA CCT TAC CAC GGC TA). PCR was performed in an iCycler Thermal Cycler (Bio-Rad Laboratories Inc.) in a final volume of $50 \mu$ l containing 2.5 U of EasyTaq DNA Polymerase (TransGen Biotech Inc.), 1× EasyTaq buffer, $2.5 \mathrm{mM}$ each dNTP, $0.4 \mu \mathrm{M}$ each primer, and $50 \mathrm{ng}$ of fungal template DNA. The PCR was performed with the following parameters: an initial preheating for $2 \mathrm{~min}$ at $94^{\circ} \mathrm{C}$; followed by 32 cycles of denaturation at $94^{\circ} \mathrm{C}$ for $30 \mathrm{~s}$, annealing at $55^{\circ} \mathrm{C}$ for $30 \mathrm{~s}$, and extension at $72^{\circ} \mathrm{C}$ for $60 \mathrm{~s}$; with a final extension at $72^{\circ} \mathrm{C}$ for $10 \mathrm{~min}$. PCR products were checked by electrophoresis in a $1 \%$ agarose gel in $1 \times$ Tris-borate-EDTA buffer, and sequenced at Wuhan Tianyi Huiyuan Biotechnology Co., Ltd.

Data analysis. All data for each fitness component were subjected to one-way analysis of variance. Mean values of each isolate within sensitivity groups and means among different groups were compared using a least significant difference test. Bivariate correlation analysis was used to analyze the relationship between the $\mathrm{EC}_{50}$ value and the mycelial growth or virulence. All data in percentage were arcsine transformed and all the sporulation data were logarithm transformed prior to analysis. All the statistical analysis tests were performed by SPSS version 19.0.

\section{Results}

Resistance profiles of the $B$. cinerea isolates to different fungicides. In total, 221 isolates of $B$. cinerea from greenhouses in eight different locations in Hubei Province were tested for sensitivity to carbendazim, diethofencarb, boscalid, fludioxonil, and cyprodinil. Results showed that isolates with resistance to carbendazim were present in all sampling sites with the resistance frequency (the percentage of individual resistant phenotype in the entire population from each location) varying from $6.45 \%$ in Huanggang (HG) to $93.62 \%$ in Jingmen (JM) (Table 1; Fig. 1). Isolates with resistance to cyprodinil were widespread in almost all of the tested locations, except HG and Xiantao (XT). The frequency was from $3.85 \%$ in Xiangyang (XY) to $89.36 \%$ in JM. However, isolates with carbendazim and diethofencarb resistance were found only in Qianjiang (QJ) and JM, with frequencies of 55.00 and $84.09 \%$, respectively. No isolates with boscalid or fludioxonil resistance were observed in the current study (Table 1; Fig. 1).

In terms of resistance phenotype, there were four phenotypes $\left(\mathrm{Car}^{\mathrm{R}} \mathrm{Die}^{\mathrm{S}} \mathrm{Cyp}^{\mathrm{S}}, \mathrm{Car}^{\mathrm{R}} \mathrm{Die}^{\mathrm{R}} \mathrm{Cyp}^{\mathrm{S}}, \mathrm{Car}^{\mathrm{R}} \mathrm{Die}^{\mathrm{S}} \mathrm{Cyp}^{\mathrm{R}}\right.$, and $\mathrm{Car}^{\mathrm{R}} \mathrm{Die}^{\mathrm{R}} \mathrm{Cyp}^{\mathrm{R}}$ ) detected from the 221 isolates. $\mathrm{Car}^{\mathrm{R}} \mathrm{Die}^{\mathrm{S}} \mathrm{Cyp}^{\mathrm{S}}$ and $\mathrm{Car}^{\mathrm{R}} \mathrm{Die}^{\mathrm{S}} \mathrm{Cyp}^{\mathrm{R}}$ were the most common phenotypes, occurring at 87.5 and $75 \%$ of the tested locations, respectively. Their frequency ranged from $2.63 \%$ at Xiaogan (XG) to $66.67 \%$ at Jingzhou (JZ), and from $3.7 \%$ at JZ to $26.32 \%$ at $\mathrm{XG}$, respectively. $\mathrm{Car}^{\mathrm{R}} \mathrm{Die}^{\mathrm{R}} \mathrm{Cyp} \mathrm{S}^{\mathrm{S}}$ and $\mathrm{Car}^{\mathrm{R}} \mathrm{Die}^{\mathrm{R}} \mathrm{Cyp}^{\mathrm{R}}$ were only detected at one (JM) and two (JM and QJ) locations, respectively. The frequency of $\operatorname{Car}^{\mathrm{R}} \operatorname{Die}^{\mathrm{R}} \mathrm{Cyp}^{\mathrm{S}}$ at JM was $4.26 \%$. For $\mathrm{Car}^{\mathrm{R}} \operatorname{Die}^{\mathrm{R}} \mathrm{Cyp}^{\mathrm{R}}$, the frequency was $74.47 \%$ at $\mathrm{JM}$ and $35 \%$ at QJ (Table 2).

Resistance is stable in carbendazim-, diethofencarb- or cyprodinilresistant isolates. After 10 successive transfers on fungicide-free PDA, all the diethofencarb-resistant isolates retained the same levels of sensitivity to the fungicide as their original generation (Table 3). For carbendazim, the $\mathrm{EC}_{50}$ values of most isolates were slightly increased but that of the isolates HBtom- 404 and HBtom- 131 were decreased. It should be noted that, even though the $\mathrm{EC}_{50}$ values of the isolates HBtom-404 and HBtom-131 were decreased, they still maintained a high resistance level to carbendazim (Table 3). A similar result was observed for 
the isolate HBtom-387 to cyprodinil, in which the $\mathrm{EC}_{50}$ value decreased from 81.18 to 17.12 but still retained resistance. For other isolates, the $\mathrm{EC}_{50}$ values to cyprodinil slightly decreased, increased, or retained the same level, indicating that these isolates still remained their resistance to cyprodinil (Table 3).

Mycelial growth, sporulation in vitro, and osmotic sensitivity. There was a great variability of mycelial growth, sporulation in vitro, or osmotic sensitivity among isolates from different groups, or even within the same sensitivity group. When compared between groups, the mean mycelial growth of the carbendazim-resistant isolates was not significantly different from that of the sensitive isolates, whereas the triple-resistant isolates, as a group, had significantly lower mycelial growth than that of the sensitive isolates $(P<0.05)$ (Table 4$)$. Within the triple-resistant isolates, the isolate HBtom-109 showed significantly lower mycelial growth compared with other isolates. When the values of mycelial growth and $\mathrm{EC}_{50}$ values to carbendazim, diethofencarb, or cyprodinil were analyzed, the correlation coefficients between mycelial growth and $\mathrm{EC}_{50}$ values of carbendazim and cyprodinil were -0.71 and -0.78 , respectively, which were significantly correlated $(P<0.01)$. However, the correlation coefficient between mycelial growth and $\mathrm{EC}_{50}$ values to diethofencarb was 0.28 , which was not significantly correlated $(P>0.05)$ (Fig. 2).

The mean value of sporulation of the carbendazim-resistant group or the triple-resistant group was not significantly different from that of the sensitive group $(P>0.05$; Table 4$)$. For osmotic sensitivity, the mean percent inhibition of the carbendazim-resistant group and the triple-resistant group was not significantly different from that of the sensitive group, either $(P>0.05$; Table 4$)$.

Virulence and sporulation in vivo. All of the isolates, including sensitive, carbendazim-resistant, or triple-resistant isolates, caused severe rot on tomato fruit. The lesion size varied in different isolates (Table 4). Isolate HBtom-301 caused the largest lesion, which was about two times larger than that caused by isolate HBtom-392. When compared among phenotype groups, the carbendazim-resistant group did not cause significantly smaller lesions than the sensitive group $(P>0.05)$ but the mean lesion size of the triple-resistant group was significantly smaller than that of the sensitive group $(P<0.05)$. When the lesion size and the level of sensitivity to fungicides were analyzed, the correlation coefficients between lesion size and the $\mathrm{EC}_{50}$ values to carbendazim, diethofencarb, and cyprodinil were $-0.45,-0.13$, and
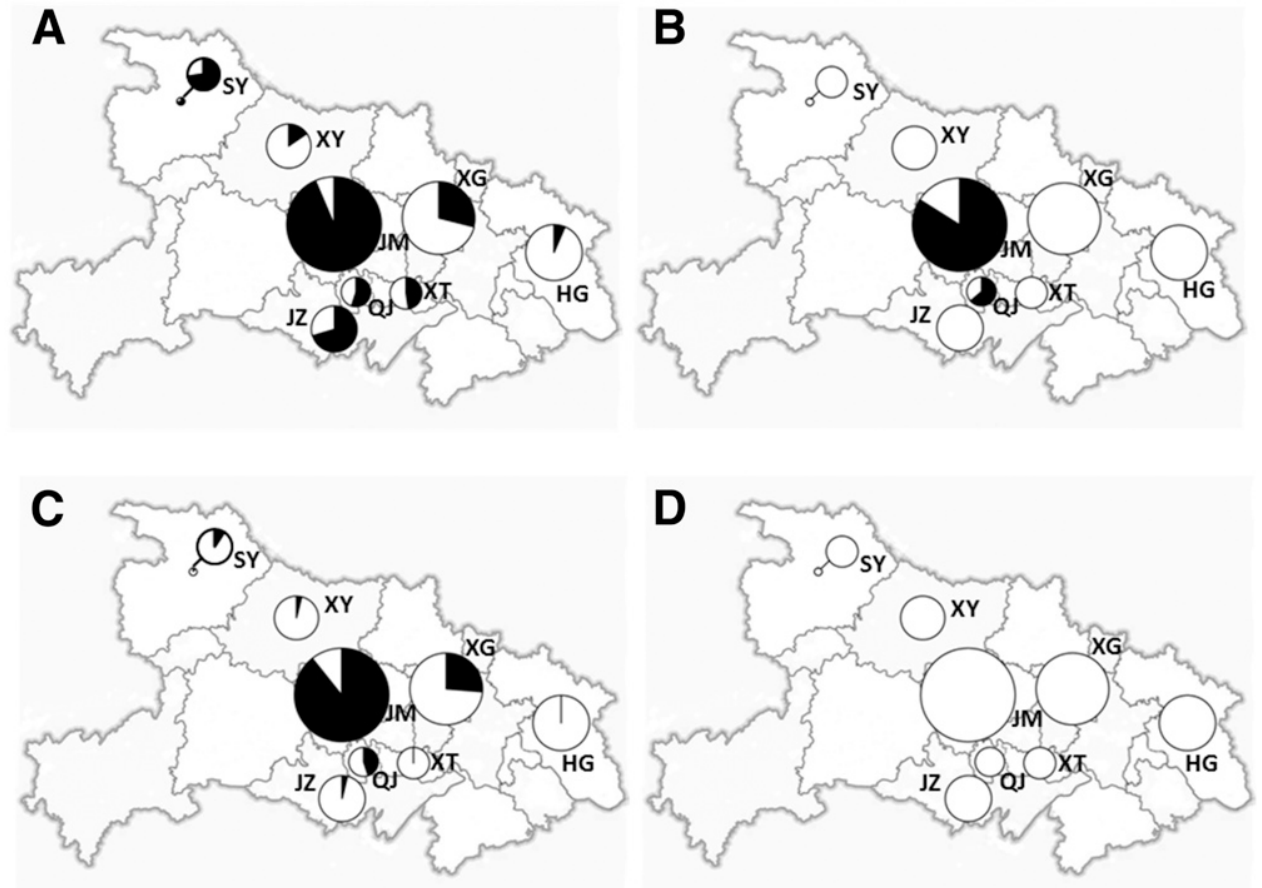

Fig. 1. Resistance profiles of Botrytis cinerea isolates from tomato in Hubei Province. Different phenotypes were indicated as sensitive (white area) or resistant (black area) to A, carbendazim; B, carbendazim and diethofencarb; C, cyprodinil; and D, fludioxonil or boscalid. The circle volume largely corresponds to the number of isolates tested in each location. $\mathrm{HG}=$ Huanggang, $\mathrm{JM}=$ Jingmen, $\mathrm{JZ}=$ Jingzhou, $\mathrm{QJ}=$ Qianjiang, $\mathrm{SY}=$ Shiyan, $\mathrm{XT}=\mathrm{Xiantao}, \mathrm{XY}=$ Xiangyang, and $\mathrm{XG}=\mathrm{Xiaogan}$.

Table 2. Frequency of fungicide-resistant phenotypes of Botrytis cinerea collected from greenhouses of tomato in Hubei Province in 2012 and 2013

\begin{tabular}{|c|c|c|c|c|c|c|}
\hline \multirow[b]{2}{*}{ Location $^{y}$} & \multirow[b]{2}{*}{$N^{\mathbf{z}}$} & \multicolumn{5}{|c|}{ Frequency of resistant phenotype $(\%)^{x}$} \\
\hline & & Car $^{S}$ Die $^{S}$ Cyp $^{S}$ & Car $^{\mathrm{R}} \mathrm{Die}^{\mathrm{S}} \mathrm{Cyp}^{\mathrm{S}}$ & Car $^{\mathrm{R}} \operatorname{Die}^{\mathrm{R}} \mathrm{Cyp}^{\mathrm{S}}$ & $\operatorname{Car}^{\mathrm{R}} \operatorname{Die}^{\mathrm{S}} \mathrm{Cyp}^{\mathrm{R}}$ & $\operatorname{Car}^{\mathrm{R}} \mathrm{Die}^{\mathrm{R}} \mathrm{Cyp}^{\mathrm{R}}$ \\
\hline HG & 31 & 93.55 & 6.45 & 0 & 0 & 0 \\
\hline JM & 47 & 6.38 & 0 & 4.26 & 14.89 & 74.47 \\
\hline $\mathrm{JZ}$ & 27 & 29.63 & 66.67 & 0 & 3.70 & 0 \\
\hline QJ & 20 & 45.00 & 10.00 & 0 & 10.00 & 35.00 \\
\hline SY & 11 & 27.27 & 63.64 & 0 & 9.09 & 0 \\
\hline XT & 21 & 52.38 & 47.62 & 0 & 0 & 0 \\
\hline XY & 26 & 84.61 & 11.54 & 0 & 3.85 & 0 \\
\hline $\mathrm{XG}$ & 38 & 71.05 & 2.63 & 0 & 26.32 & 0 \\
\hline Total & 221 & 50.69 & 19.46 & 0.90 & 9.95 & 19.00 \\
\hline
\end{tabular}

${ }^{\mathrm{x}} \mathrm{Car}=$ carbendazim, Die = diethofencarb, and Cyp = cyprodinil; superscripts R and S indicate resistant and sensitive, respectively.

${ }^{\mathrm{y}} \mathrm{HG}=$ Huanggang, JM = Jingmen, JZ = Jingzhou, QJ = Qianjiang, SY = Shiyan, XT = Xiantao, XY = Xiangyang, and XG = Xiaogan.

${ }^{\mathrm{z}}$ Number of isolates. 
-0.34 , respectively, which were not significantly correlated $(P>0.05$; Fig. 2).

The ability of sporulation in vivo was different among isolates (Table 4). When compared among phenotype groups, the sporulation of the carbendazim-resistant group and the triple-resistant group was not significantly different from that of the sensitive group $(P>0.05$; Table 4).

Fungicide control efficacy for resistant isolates. Three isolates resistant to carbendazim, diethofencarb, and cyprodinil as well as three sensitive isolates were chosen for assays of fungicide control efficacy on detached fruit. Three sensitive isolates were completely inhibited by carbendazim, or carbendazim and diethofencarb, but not cyprodinil. For cyprodinil, although the disease incidences of the three sensitive isolates were $5.56,22.22$, and $38.89 \%$, the disease still could be controlled effectively with control efficacies of 94.00 , 89.68 , and $88.45 \%$, respectively (Table 5). In contrast, no matter what kinds of fungicides (carbendazim, carbendazim and diethofencarb, or cyprodinil) were sprayed at the highest rates of recommendation, three triple-resistant isolates caused $100 \%$ disease incidence after 3 days and most of the control efficacies were below zero, except isolate HBtom404. For isolate HBtom-404, the control efficacies of carbendazim, carbendazim and diethofencarb, and cyprodinil were $-14.7 \%, 3.82$, and $20.70 \%$, respectively (Table 5).

Resistance conferred by point mutations at codon 198 of the TUB2 gene. Sequence analysis of the partial TUB2 gene from all
10 carbendazim-resistant isolates revealed single nucleotide changes at codon 198. Nine isolates showed the mutation from GAG to GTG which caused the amino acid change from glutamic acid to valine (E198V), and the other one showed the mutation from GAG to GCG changing glutamic acid to alanine (E198A). For the five isolates resistant to carbendazim and diethofencarb, all possessed the mutation from GAG to AAG at codon 198 which altered the glutamic acid to lysine (E198K).

\section{Discussion}

In this study, the sensitivity of $B$. cinerea on tomato in Hubei to fungicides was tested. Results showed that carbendazim resistance was widespread in Hubei Province, which is similar to other studies from eastern provinces (Jiangsu, Zhejiang, and Shandong) of China and other countries (Fernández-Ortuño et al. 2014a; Sun et al. 2010; Weber 2011; Zhang et al. 2009b). However, the mean frequency was $49.32 \%$, which was lower than the reported $80.9 \%$ at Jiangsu and Zhejiang in 2006 and $100 \%$ at Jiangsu in 2008 and Shandong in 2007 (Sun et al. 2010; Zhang et al. 2009b). One reason for the difference might be that the isolates of $B$. cinerea were collected from tomato in Hubei, a less-developed area compared with Jiangsu, Zhejiang, and Shandong. In Jiangsu, Zhejiang, and Shandong, the application of carbendazim was more frequent and over a longer period of time.

Considering the fact that diethofencarb was used in mixtures with carbendazim in China (Zhang et al. 2009b), resistance to diethofencarb

Table 3. Stability of resistance of Botrytis cinerea isolates after 10 consecutive transfers on fungicide-free medium

\begin{tabular}{|c|c|c|c|c|c|c|c|}
\hline \multirow[b]{3}{*}{ Isolates } & \multirow[b]{3}{*}{ Phenotypes $^{\mathrm{z}}$} & \multicolumn{6}{|c|}{ EC $_{50}$ values $(\mu \mathrm{g} / \mathrm{ml})^{y}$} \\
\hline & & \multicolumn{2}{|c|}{ Car } & \multicolumn{2}{|c|}{ Die } & \multicolumn{2}{|c|}{ Сур } \\
\hline & & Original & 10th & Original & 10th & Original & 10th \\
\hline HBtom-404 & $\mathrm{Car}^{\mathrm{R}} \mathrm{Die}^{\mathrm{R}} \mathrm{Cyp}^{\mathrm{R}}$ & 69.77 & 64.35 & $>100$ & $>100$ & $>100$ & $>100$ \\
\hline HBtom-131 & $\mathrm{Car}^{\mathrm{R}} \mathrm{Die}^{\mathrm{R}} \mathrm{Cyp}^{\mathrm{R}}$ & $>100$ & 51.71 & $>100$ & $>100$ & 65.24 & $>100$ \\
\hline HBtom-370 & $\mathrm{Car}^{\mathrm{R}} \mathrm{Die}^{\mathrm{R}} \mathrm{Cyp} \mathrm{p}^{\mathrm{R}}$ & 55.2 & 64.36 & $>100$ & $>100$ & 18.84 & 16.91 \\
\hline HBtom-109 & $\operatorname{Car}^{R} \operatorname{Die}^{R} C^{2 y p}{ }^{R}$ & 52.79 & 69.18 & $>100$ & $>100$ & $>100$ & $>100$ \\
\hline HBtom-387 & $\mathrm{Car}^{\mathrm{R}} \mathrm{Die}^{\mathrm{R}} \mathrm{Cyp}^{\mathrm{R}}$ & 58.46 & 59.87 & $>100$ & $>100$ & 81.18 & 17.12 \\
\hline HBtom-392 & $\mathrm{Car}^{\mathrm{R}} \mathrm{Die}^{\mathrm{R}} \mathrm{Cyp}^{\mathrm{R}}$ & 43.03 & 54.21 & $>100$ & $>100$ & 39.47 & 19.26 \\
\hline HBtom-81 & $\mathrm{Car}^{\mathrm{R}} \mathrm{Die}^{\mathrm{S}} \mathrm{Cyp}^{\mathrm{S}}$ & $>100$ & $>100$ & nd & nd & nd & nd \\
\hline HBtom-173 & $\mathrm{Car}^{\mathrm{R}} \mathrm{Die}^{\mathrm{S}} \mathrm{Cyp}^{\mathrm{S}}$ & 53.39 & 84.92 & nd & nd & nd & nd \\
\hline HBtom-310 & $\mathrm{Car}^{\mathrm{R}} \mathrm{Die}^{\mathrm{S}} \mathrm{Cyp}^{\mathrm{S}}$ & 40.71 & 87.85 & nd & nd & nd & nd \\
\hline
\end{tabular}

${ }^{\mathrm{y}} \mathrm{EC}_{50}=$ fungicide concentration that results in $50 \%$ inhibition of mycelial growth relative to the control.

${ }^{\mathrm{z}} \mathrm{Car}=$ carbendazim, Die = diethofencarb, and Cyp = cyprodinil; superscripts R and S indicate resistant and sensitive, respectively; nd = not determined.

Table 4. Determination of fitness of Botrytis cinerea isolates with different resistant phenotypes ${ }^{\mathrm{w}}$

\begin{tabular}{|c|c|c|c|c|c|c|}
\hline \multirow[b]{2}{*}{ Isolates } & \multirow[b]{2}{*}{ Phenotypes $^{x}$} & \multicolumn{3}{|c|}{ In vitro experiments } & \multicolumn{2}{|c|}{ In vivo experiments } \\
\hline & & Mycelial growth (cm) & Osmotic sensitivity $^{\mathbf{y}}$ & Sporulation $\left(\times 10^{5} / \mathrm{cm}^{2}\right)^{\mathrm{z}}$ & Lesion size (cm) & Sporulation $\left(\times 10^{5} / \mathrm{cm}^{2}\right)^{\mathrm{z}}$ \\
\hline HBtom-103 & $\mathrm{Car}^{\mathrm{S}} \mathrm{Die}^{\mathrm{S}} \mathrm{Cyp}^{\mathrm{S}}$ & $7.56 \pm 0.17 b$ & $83.21 \pm 2.37 \mathrm{bc}$ & $4.96 \pm 0.35 \mathrm{ab}$ & $1.92 \pm 0.16 b c$ & $2.49 \pm 0.89 a$ \\
\hline HBtom-188 & $\mathrm{Car}^{\mathrm{S}} \mathrm{Die}^{\mathrm{S}} \mathrm{Cyp}^{\mathrm{S}}$ & $7.94 \pm 0.03 \mathrm{a}$ & $78.18 \pm 0.99 \mathrm{~cd}$ & $7.68 \pm 0.88 \mathrm{a}$ & $2.21 \pm 0.15 b c$ & $0.94 \pm 0.45 b$ \\
\hline HBtom-301 & $\mathrm{Car}^{\mathrm{S}} \mathrm{Die}^{\mathrm{S}} \mathrm{Cyp}^{\mathrm{S}}$ & $7.91 \pm 0.04 \mathrm{ab}$ & $77.39 \pm 2.72 \mathrm{~cd}$ & $0.97 \pm 0.32 \mathrm{~cd}$ & $3.18 \pm 0.28 \mathrm{a}$ & $0.53 \pm 0.22 \mathrm{ab}$ \\
\hline HBtom-331 & $\mathrm{Car}^{\mathrm{S}} \mathrm{Die}^{\mathrm{S}} \mathrm{Cyp}^{\mathrm{S}}$ & $7.89 \pm 0.05 \mathrm{ab}$ & $82.48 \pm 1.17 \mathrm{bc}$ & $0.82 \pm 0.28 \mathrm{bcd}$ & $2.94 \pm 0.23 \mathrm{a}$ & $0.26 \pm 0.07 \mathrm{ab}$ \\
\hline HBtom-362 & $\mathrm{Car}^{\mathrm{S}} \mathrm{Die}^{\mathrm{S}} \mathrm{Cyp}^{\mathrm{S}}$ & $7.84 \pm 0.06 \mathrm{ab}$ & $79.61 \pm 1.05 \mathrm{~cd}$ & $0.85 \pm 0.33 \mathrm{~d}$ & $2.15 \pm 0.12 b c$ & $2.95 \pm 0.96 \mathrm{a}$ \\
\hline HBtom-537 & $\mathrm{Car}^{\mathrm{S}} \mathrm{Die}^{\mathrm{S}} \mathrm{Cyp}^{\mathrm{S}}$ & $7.71 \pm 0.13 \mathrm{ab}$ & $74.88 \pm 1.89 \mathrm{de}$ & $4.94 \pm 1.72 b$ & $1.84 \pm 0.05 c$ & $1.18 \pm 0.29 \mathrm{ab}$ \\
\hline HBtom-81 & $\mathrm{Car}^{\mathrm{R}} \mathrm{Die}^{\mathrm{S}} \mathrm{Cyp}^{\mathrm{S}}$ & $7.62 \pm 0.09 \mathrm{ab}$ & $80.13 \pm 0.45 c$ & $1.06 \pm 0.18 \mathrm{bcd}$ & $2.32 \pm 0.15 b$ & $1.80 \pm 0.75 \mathrm{ab}$ \\
\hline HBtom-173 & $\mathrm{Car}^{\mathrm{R}} \mathrm{Die}^{\mathrm{S}} \mathrm{Cyp} \mathrm{S}^{\mathrm{S}}$ & $7.61 \pm 0.15 b$ & $83.64 \pm 0.96 \mathrm{bc}$ & $0.09 \pm 0.02$ ef & $2.13 \pm 0.17 b c$ & $1.62 \pm 0.48 \mathrm{ab}$ \\
\hline HBtom-310 & $\mathrm{Car}^{\mathrm{R}} \mathrm{Die}^{\mathrm{S}} \mathrm{Cyp}^{\mathrm{S}}$ & $6.97 \pm 0.13 \mathrm{~cd}$ & $76.84 \pm 0.88 \mathrm{~cd}$ & $0.11 \pm 0.02 \mathrm{e}$ & $2.08 \pm 0.18 b c$ & $0.72 \pm 0.40 \mathrm{bc}$ \\
\hline HBtom-109 & $\mathrm{Car}^{\mathrm{R}} \mathrm{Die}^{\mathrm{R}} \mathrm{Cyp}^{\mathrm{R}}$ & $5.87 \pm 0.04 \mathrm{f}$ & $71.23 \pm 1.94 \mathrm{de}$ & $2.55 \pm 0.16 \mathrm{~b}$ & $1.51 \pm 0.07 \mathrm{~cd}$ & $1.80 \pm 0.85 \mathrm{ab}$ \\
\hline HBtom-131 & $\mathrm{Car}^{\mathrm{R}} \mathrm{Die}^{\mathrm{R}} \mathrm{Cyp}^{\mathrm{R}}$ & $7.11 \pm 0.09 \mathrm{~cd}$ & $83.79 \pm 1.15 b c$ & $1.36 \pm 0.41 \mathrm{~cd}$ & $2.28 \pm 0.20 b c$ & $2.58 \pm 1.22 \mathrm{a}$ \\
\hline HBtom-370 & $\operatorname{Car}^{R} \operatorname{Die}^{R} C y p^{R}$ & $6.80 \pm 0.25 \mathrm{~d}$ & $90.17 \pm 1.90 \mathrm{a}$ & $0.10 \pm 0.04$ ef & $1.57 \pm 0.05 \mathrm{~cd}$ & $0.09 \pm 0.09 \mathrm{c}$ \\
\hline HBtom-387 & $\operatorname{Car}^{R} \operatorname{Die}^{R} C y p^{R}$ & $7.04 \pm 0.12 \mathrm{~cd}$ & $89.28 \pm 1.20 \mathrm{a}$ & $1.78 \pm 0.33 \mathrm{bc}$ & $1.58 \pm 0.09 \mathrm{~cd}$ & $1.44 \pm 0.69 b$ \\
\hline HBtom-392 & $\mathrm{Car}^{\mathrm{R}} \mathrm{Die}^{\mathrm{R}} \mathrm{Cyp}^{\mathrm{R}}$ & $6.92 \pm 0.10 \mathrm{~d}$ & $80.74 \pm 0.75 b c$ & $0.08 \pm 0.03 \mathrm{f}$ & $1.38 \pm 0.10 \mathrm{~d}$ & $0.08 \pm 0.04 \mathrm{bc}$ \\
\hline HBtom-404 & $\operatorname{Car}^{\mathrm{R}} \mathrm{Die}^{\mathrm{R}} \mathrm{Cyp} \mathrm{p}^{\mathrm{R}}$ & $7.28 \pm 0.07 \mathrm{c}$ & $84.87 \pm 0.84 b$ & $2.76 \pm 0.66 b$ & $1.88 \pm 0.11 \mathrm{c}$ & $1.61 \pm 0.61 \mathrm{ab}$ \\
\hline
\end{tabular}

${ }^{\mathrm{w}}$ Data shown are the means of two independent experiments. Mean \pm standard error; values followed by the same letter within a column are not significantly different according to the one-way analysis of variance with least significant difference test at $P=0.05$.

$\times$ Car = carbendazim, Die = diethofencarb, and Cyp = cyprodinil; superscripts R and S indicate resistant and sensitive, respectively.

y Percent inhibition of mycelial growth on potato dextrose agar amended with $8 \% \mathrm{NaCl}$ relative to the unamended control. Data were arcsine-transformed before analysis.

${ }^{\mathrm{z}}$ Data were logarithm-transformed before analysis. 
was investigated only in the carbendazim-resistant isolates. In contrast to widespread carbendazim resistance, isolates with dual resistance to carbendazim and diethofencarb were found only at JM and QJ in this study, suggesting that the mixture did not lose its efficacy to control B. cinerea at most locations in Hubei. However, because the resistance occurred at a few locations, the application of this mixture must be restricted to locations where the resistance was not detected. Meanwhile, the development of resistance should be monitored in a timely fashion.
Isolates with resistance to cyprodinil were detected at six of eight locations, showing that resistance to cyprodinil was widely distributed in Hubei. AP, a novel family of botryticide, were introduced into China in 2000, and resistant $B$. cinerea was detected in 2003, just 3 years after its application in eastern China (Zhang et al. 2009a). Development of resistance to AP was also reported in $B$. cinerea populations from the United States and Germany (Fernández-Ortuño et al. 2013b, 2014a; Weber 2011). In order to reduce the selection pressure
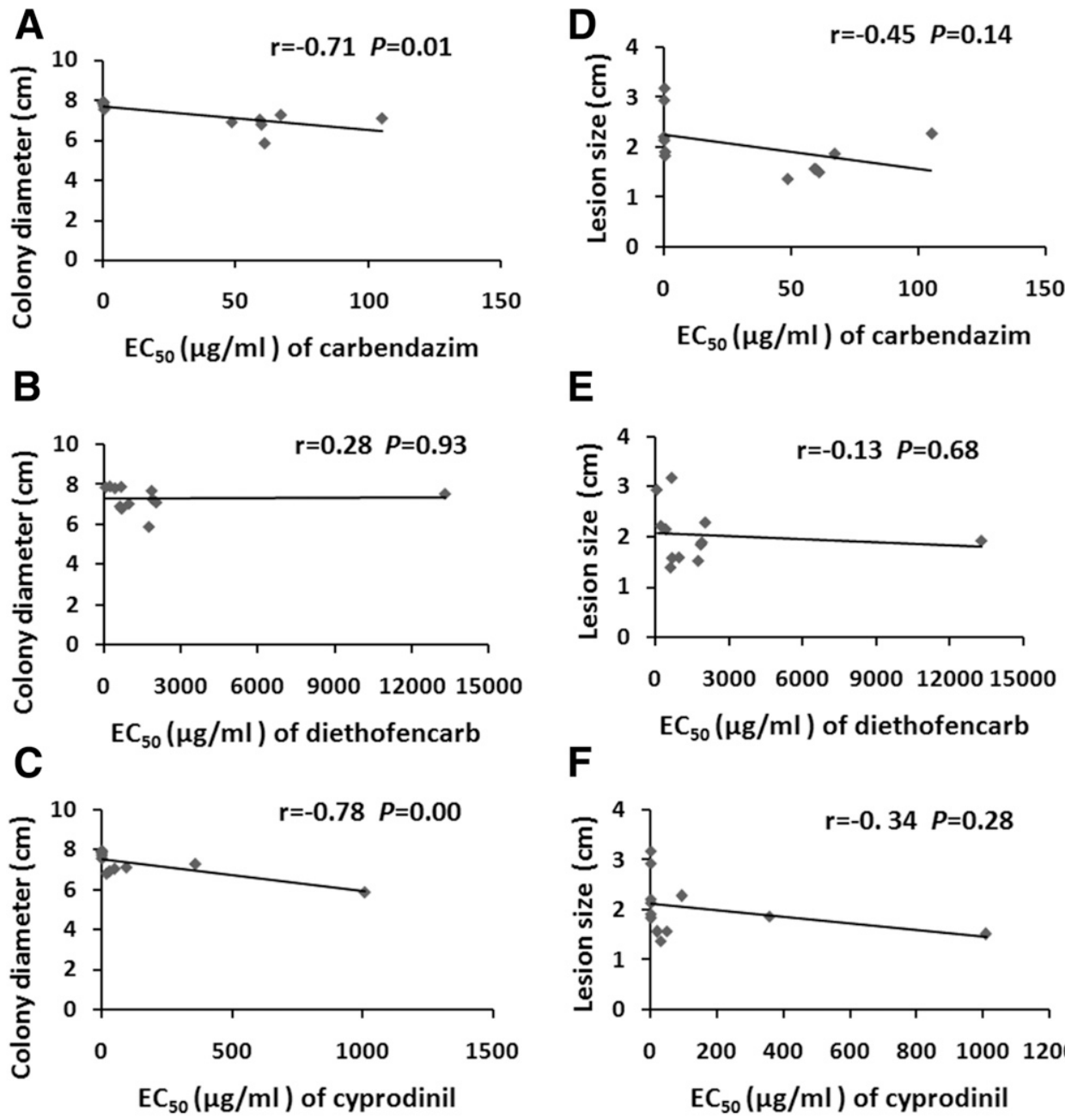

E
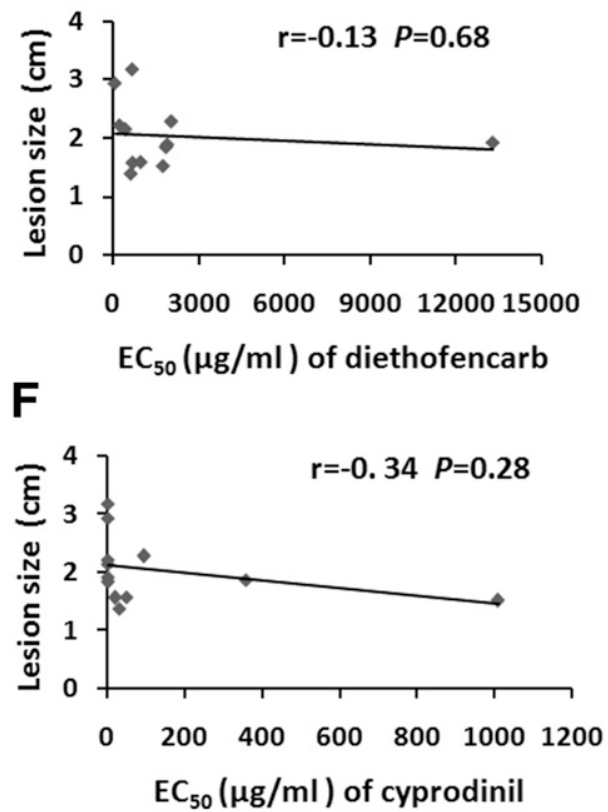

Fig. 2. Correlation analysis between mycelial growth and the level of sensitivity to A, carbendazim; B, diethofencarb, and C, cyprodinil; and virulence and the level of sensitivity to D, carbendazim; E, diethofencarb; and F, cyprodinil. Colony diameter indicates the colony diameter on potato dextrose agar for 3 days; lesion size indicates the lesion size on tomato fruit for 3 days. $\mathrm{EC}_{50}=$ the concentration at which mycelial growth is inhibited by $50 \%$.

Table 5. Disease incidence caused by resistant isolates and their control efficacy on detached fruit treated with formulated fungicides ${ }^{\mathrm{w}}$

\begin{tabular}{|c|c|c|c|c|c|c|c|}
\hline \multirow[b]{2}{*}{ Isolates } & \multirow[b]{2}{*}{ Phenotypes ${ }^{z}$} & \multicolumn{3}{|c|}{ Disease incidence $^{x}$} & \multicolumn{3}{|c|}{ Control efficacy $(\%)^{y}$} \\
\hline & & Car & Die & Cyp & Car & Die & Сур \\
\hline HBtom-188 & $\mathrm{Car}^{\mathrm{S}} \mathrm{Die}^{\mathrm{S}} \mathrm{Cyp}^{\mathrm{S}}$ & $0 \pm 0 \mathrm{~b}$ & $0 \pm 0 \mathrm{~b}$ & $5.56 \pm 5.56 \mathrm{c}$ & $100 \pm 0 \mathrm{a}$ & $100 \pm 0 \mathrm{a}$ & $94.00 \pm 1.26 \mathrm{a}$ \\
\hline HBtom-362 & $\mathrm{Car}^{\mathrm{S}} \mathrm{Die}^{\mathrm{S}} \mathrm{Cyp}^{\mathrm{s}}$ & $0 \pm 0 b$ & $0 \pm 0 \mathrm{~b}$ & $22.22 \pm 11.11 b c$ & $100 \pm 0 \mathrm{a}$ & $100 \pm 0 \mathrm{a}$ & $89.68 \pm 2.11 \mathrm{a}$ \\
\hline HBtom-301 & $\mathrm{Car}^{\mathrm{S}} \mathrm{Die}^{\mathrm{S}} \mathrm{Cyp}^{\mathrm{S}}$ & $0 \pm 0 \mathrm{~b}$ & $0 \pm 0 \mathrm{~b}$ & $38.89 \pm 5.56 b$ & $100 \pm 0 \mathrm{a}$ & $100 \pm 0 \mathrm{a}$ & $88.45 \pm 2.83 \mathrm{a}$ \\
\hline HBtom-131 & $\mathrm{Car}^{\mathrm{R}} \mathrm{Die}^{\mathrm{R}} \mathrm{Cyp}^{\mathrm{R}}$ & $100 \pm 0 \mathrm{a}$ & $100 \pm 0 a$ & $100 \pm 0 a$ & $-18.52 \pm 5.34 \mathrm{~b}$ & $-2.02 \pm 4.41 \mathrm{~b}$ & $-4.58 \pm 4.00 c$ \\
\hline HBtom-392 & $\mathrm{Car}^{\mathrm{R}} \mathrm{Die}^{\mathrm{R}} \mathrm{Cyp}^{\mathrm{R}}$ & $100 \pm 0 \mathrm{a}$ & $100 \pm 0 \mathrm{a}$ & $100 \pm 0 \mathrm{a}$ & $-52.58 \pm 7.01 \mathrm{c}$ & $-34.66 \pm 7.38 c$ & $-22.57 \pm 6.16 \mathrm{~d}$ \\
\hline HBtom-404 & $\mathrm{Car}^{\mathrm{R}} \mathrm{Die}^{\mathrm{R}} \mathrm{Cyp}^{\mathrm{R}}$ & $100 \pm 0 \mathrm{a}$ & $100 \pm 0 \mathrm{a}$ & $100 \pm 0 \mathrm{a}$ & $-14.78 \pm 3.95 b$ & $3.82 \pm 3.44 b$ & $20.70 \pm 4.02 b$ \\
\hline
\end{tabular}

${ }^{\mathrm{w}}$ Data are the means \pm standard errors of two independent experiments. Values followed by the same letter within a column are not significantly different according to the one-way analysis of variance with least significant difference test at $P=0.05$.

${ }^{x}$ Disease incidence was expressed as the percentage of wounds infected compared with the total number of wounds inoculated.

$y$ Control efficacy was expressed as the percentage of the mean diameter of the lesions in control minus the mean diameter in the treatment divided by the mean diameter in the control.

${ }^{\mathrm{z}} \mathrm{Car}=$ carbendazim, $\mathrm{Die}=$ diethofencarb, and $\mathrm{Cyp}=$ cyprodinil; superscripts $\mathrm{R}$ and $\mathrm{S}$ indicate resistant and sensitive, respectively. 
of fungicides, the rotation or mixture of AP with other fungicides with different mode of actions (e.g., PP) should be used to control gray mold. At locations where resistance is still not detected, rotation with other fungicides would be especially important (Forster and Staub 1996).

Isolates resistant to boscalid or fludioxonil were not detected in this study. Boscalid, as a new site-specific fungicide, was just registered to control gray mold in recent years (Wang et al. 2009), and fludioxonil, registered to control gray mold only on some ornamental flowers, was also introduced in recent years (Hamada et al. 2011). The limited application of these fungicides might be the reason why resistant isolates were not detected. It is also reasonable that the frequency of resistance was too low to be detected in current samples. The lack of resistance to boscalid or fludioxonil indicated that the application of boscalid or fludioxonil is still effective to control $\mathrm{B}$. cinerea at present. Nevertheless, isolates of $B$. cinerea with resistance to boscalid have been reported in many other countries soon after its application, suggesting that $B$. cinerea was a high risk pathogen for the development of boscalid resistance (Bardas et al. 2010; FernándezOrtuño et al. 2012; Walker et al. 2013; Yin et al. 2011). Furthermore, fludioxonil-resistant isolates have been detected in the fields in France, Germany, and the United States in recent years (Fernández-Ortuño et al. 2013a, 2014b,c; Kretschmer et al. 2009). Therefore, attention still needs to be paid when boscalid or fludioxonil is applied, and tank mixtures with fungicides with different modes of action might prevent or delay the occurrence of the resistance.

$B$. cinerea, as a high-risk pathogen for the development of fungicide resistance, has developed multiple fungicide resistances, which dramatically decreased the fungicide efficiency in practice (Kretschmer et al. 2009). In this study, four phenotypes of resistance were detected (i.e., $\mathrm{Car}^{\mathrm{R}} \mathrm{Die}^{\mathrm{S}} \mathrm{Cyp}^{\mathrm{S}}, \mathrm{Car}^{\mathrm{R}} \mathrm{Die}^{\mathrm{R}} \mathrm{Cyp}^{\mathrm{S}}, \mathrm{Car}^{\mathrm{R}} \mathrm{Die}^{\mathrm{S}} \mathrm{Cyp}^{\mathrm{R}}$, and $\mathrm{Car}^{\mathrm{R}} \mathrm{Die}^{\mathrm{R}} \mathrm{Cyp}^{\mathrm{R}}$ ). Among these phenotypes, $\mathrm{Car}^{\mathrm{R}} \mathrm{Die}^{\mathrm{S}} \mathrm{Cyp}^{\mathrm{S}}$ and $\mathrm{Car}^{\mathrm{R}} \mathrm{Die}^{\mathrm{S}} \mathrm{Cyp}^{\mathrm{R}}$ were widely detected, while $\operatorname{Car}^{R}{ }^{R} e^{R} C y p^{S}$ was found only in JM and $\operatorname{Car}^{R} \operatorname{Die}^{R} C y p^{R}$ was found at JM and QJ. Interestingly, there was a dominant resistance profile at every location. A majority of locations faced the problem of carbendazim and cyprodinil resistance. JM and QJ cities were confronted with the issue of carbendazim, diethofencarb, and cyprodinil resistance, especially $\mathrm{JM}$. To manage the resistant population of $B$. cinerea, the use of the three fungicides should be limited and new fungicides with novel mode of action (e.g., fludioxonil and boscalid) ought to be introduced. In addition, biological control and agricultural measures that could decrease the relative humidity of greenhouses and the disease inoculum should be adopted.

More interestingly, isolates merely resistant to cyprodinil were not obtained but the resistance to cyprodinil was always associated with the resistance to carbendazim in this study. This result demonstrated that all the cyprodinil-resistant isolates may have been derived from the carbendazim-resistant isolates, indicating that carbendazim-resistant isolates had a higher risk to develop the resistance to cyprodinil than the sensitive ones. Such a stepwise pattern of resistance development was described recently in the United States, where the phenotypes of multiple fungicide resistance of $B$. cinerea from blackberry and strawberry didn't evolve randomly but were more likely to have evolved from previously resistant subpopulations ( $\mathrm{Li}$ et al. 2014a). These findings were constructive for understanding the evolution of fungicide resistance of B. cinerea.

Stability of the resistances in isolates resistant to carbendazim and to carbendazim, diethofencarb, and cyprodinil showed that these resistances developed through genetic variations. Furthermore, the fitness study showed that there were no significant differences between the sensitive group and carbendazim-resistant group at mycelial growth, osmotic sensitivity to $\mathrm{NaCl}$, sporulation both in vitro and in vivo, and virulence, which indicated that the isolates resistant to carbendazim had fitness similar to that of the sensitive isolates. This result was consistent with that of Malandrakis et al. (2011), who found that there was no significant difference between isolates resistant and sensitive to zoxamide (sharing the same mode of action with carbendazim). However, the triple-resistant group had some disadvantages when colonizing the hosts compared with sensitive group. Despite this, there was no significant difference between these two groups for osmotic sensitivity to
$\mathrm{NaCl}$ or sporulation either in vivo or in vitro. $B$. cinerea with resistance to a single fungicide or all three fungicides was also detected and showed little fitness penalty in other studies (Bardas et al. 2008; Malandrakis et al. 2011; Sun et al. 2010), suggesting that isolates resistant to carbendazim, diethofencarb, and cyprodinil can still compete with the sensitive isolates.

Resistances to carbendazim and to carbendazim and diethofencarb were associated with mutations of the gene TUB2 (Malandrakis et al 2011; Yarden and Katan 1993). In this study, all 10 carbendazimresistant isolates harbored the mutations. Nine isolates showed the mutation E198V and the other one showed the mutation E198A. Previous reports showed that E198A and E198V were two major benzimidazole-resistant mutations and both of them could confer high resistance to carbendazim (Banno et al. 2008). The higher frequency of the E198V mutation indicated that it was more competitive than the other mutation, and further research is needed to clarify this phenomenon. For the five isolates resistant to carbendazim and diethofencarb, all possessed the mutation E198K. To the best of our knowledge, this is the first report that the mutation E198K was involved in resistance in $B$. cinerea to carbendazim and diethofencarb in China. The isolates moderately resistant to carbendazim and insensitive to diethofencarb frequently revealed the mutation F200Y (Yarden and Katan 1993) but it was not detected in this study. Further work is needed to explore this issue in the future.

In conclusion, field resistance of $B$. cinerea to carbendazim and cyprodinil has occurred widely in most of the monitored greenhouses in Hubei Province. Even though the resistant isolates had some difficulty colonizing the host, they were still competitive to a certain degree and there is a risk of the spread of the resistant populations. In practice, resistance has not been detected for fludioxonil and boscalid and they should be introduced into the program, which might be a good choice to manage the resistance problems on greenhouse tomato in Hubei.

\section{Acknowledgments}

This work was supported by the Special Fund for Agro-Scientific Research in the Public Interest (numbers 201303023 and 201303025).

\section{Literature Cited}

Banno, S., Fukumori, F., Ichiishi, A., Okada, K., Uekusa, H., Kimura, M., and Fujimura, M. 2008. Genotyping of benzimidazole-resistant and dicarboximideresistant mutations in Botrytis cinerea using real-time polymerase chain reaction assays. Phytopathology 98:397-404.

Bardas, G. A., Myresiotis, C. K., and Karaoglanidis, G. S. 2008. Stability and fitness of anilinopyrimidine-resistant strains of Botrytis cinerea. Phytopathology 98: 443-450.

Bardas, G. A., Veloukas, T., Koutita, O., and Karaoglanidis, G. S. 2010. Multiple resistance of Botrytis cinerea from kiwifruit to SDHIs, QoIs and fungicides of other chemical groups. Pest Manage. Sci. 66:967-973.

Bolton, A. T. 1976. Fungicide resistance in Botrytis cinerea, the result of selective pressure on resistant strains already present in nature. Can. J. Plant Sci. 56:861-864

Brent, K. J., Hollomon, D. W., and Federation, G. C. P. 1998. Fungicide Resistance: The Assessment of Risk. Global Crop Protection Federation Brussels, Belgium

Chi, M.-H., Park, S.-Y., and Lee, Y.-H. 2009. A quick and safe method for fungal DNA extraction. Plant Pathol. J. 25:108-111.

Elad, Y., Yunis, H., and Katan, T. 1992. Multiple fungicide resistance to benzimidazoles, dicarboximides and diethofencarb in field isolates of Botrytis cinerea in Israel. Plant Pathol. 41:41-46.

Fan, X., Zhang, J., Yang, L., Wu, M., Chen, W., and Li, G. 2015. Development of PCR-Based assays for detecting and differentiating three species of Botrytis infecting broad bean. Plant Dis. 99:691-698.

Fernández-Ortuño, D., Bryson, P. K., Grabke, A., and Schnabel, G. 2013a. First report of fludioxonil resistance in Botrytis cinerea from a strawberry field in Virginia. Plant Dis. 97:848.

Fernández-Ortuño, D., Chen, F., and Schnabel, G. 2012. Resistance to pyraclostrobin and boscalid in Botrytis cinerea isolates from strawberry fields in the Carolinas. Plant Dis. 96:1198-1203.

Fernández-Ortuño, D., Chen, F., and Schnabel, G. 2013b. Resistance to cyprodinil and lack of fludioxonil resistance in Botrytis cinerea isolates from strawberry in North and South Carolina. Plant Dis. 97:81-85.

Fernández-Ortuño, D., Grabke, A., Bryson, P. K., Amiri, A., Peres, N. A., and Schnabel, G. 2014a. Fungicide resistance profiles in Botrytis cinerea from strawberry fields of seven Southern U.S. states. Plant Dis. 98:825-833.

Fernández-Ortuño, D., Grabke, A., Bryson, P. K., Beasley, E. D., Fall, L. A., Brannen, P. M., and Schnabel, G. 2014b. First report of fludioxonil resistance in Botrytis cinerea from a blackberry field in Georgia. Plant Dis. 98:848. 
Fernández-Ortuño, D., Grabke, A., Bryson, P. K., Rouse, R. J., Rollins, P., and Schnabel, G. 2014c. First report of fludioxonil resistance in Botrytis cinerea, the causal agent of gray mold, from strawberry fields in Maryland and South Carolina. Plant Dis. 98:692.

Forster, B., and Staub, T. 1996. Basis for use strategies of anilinopyrimidine and phenylpyrrole fungicides against Botrytis cinerea. Crop Prot. 15:529-537.

Fritz, R., Lanen, C., Colas, V., and Leroux, P. 1997. Inhibition of methionine biosynthesis in Botrytis cinerea by the anilinopyrimidine fungicide pyrimethanil. Pestic. Sci. 49:40-46.

Hamada, M. S., Yin, Y., and Ma, Z. 2011. Sensitivity to iprodione, difenoconazole and fludioxonil of Rhizoctonia cerealis isolates collected from wheat in China. Crop Prot. 30:1028-1033.

Jespers, A. B. K., and De Waard, M. A. 1995. Effect of fenpiclonil on phosphorylation of glucose in Fusarium sulphureum. Pestic. Sci. 44:167-175.

Kim, Y. K., and Xiao, C. L. 2011. Stability and fitness of pyraclostrobin- and boscalid-resistant phenotypes in field isolates of Botrytis cinerea from apple. Phytopathology 101:1385-1391.

Kretschmer, M., Leroch, M., Mosbach, A., Walker, A. S., Fillinger, S., Mernke, D., Schoonbeek, H. J., Pradier, J. M., Leroux, P., De Waard, M. A., and Hahn, M. 2009. Fungicide-driven evolution and molecular basis of multidrug resistance in field populations of the grey mould fungus Botrytis cinerea. PLoS Pathog. 5:e1000696.

Lalève, A., Gamet, S., Walker, A. S., Debieu, D., Toquin, V., and Fillinger, S. 2014. Site-directed mutagenesis of the P225, N230 and H272 residues of succinate dehydrogenase subunit B from Botrytis cinerea highlights different roles in enzyme activity and inhibitor binding. Environ. Microbiol. 16: 2253-2266.

Leroux, P., Chapeland, F., Desbrosses, D., and Gredt, M. 1999. Patterns of crossresistance to fungicides in Botryotinia fuckeliana (Botrytis cinerea) isolates from French vineyards. Crop Prot. 18:687-697.

Leroux, P., Fritz, R., Debieu, D., Albertini, C., Lanen, C., Bach, J., Gredt, M., and Chapeland, F. 2002. Mechanisms of resistance to fungicides in field strains of Botrytis cinerea. Pest Manage. Sci. 58:876-888.

Leroux, P., Gredt, M., Leroch, M., and Walker, A. S. 2010. Exploring mechanisms of resistance to respiratory inhibitors in field strains of Botrytis cinerea, the causal agent of gray mold. Appl. Environ. Microbiol. 76:6615-6630.

Li, X., Fernández-Ortuño, D., Chen, S., Grabke, A., Luo, C.-X., Bridges, W. C., and Schnabel, G. 2014a. Location-specific fungicide resistance profiles and evidence for stepwise accumulation of resistance in Botrytis cinerea. Plant Dis. 98:1066-1074.

Li, X., Fernández-Ortuño, D., Grabke, A., and Schnabel, G. 2014b. Resistance to fludioxonil in Botrytis cinerea isolates from blackberry and strawberry. Phytopathology 104:724-732.

Luo, C.-X., Hanamura, H., Sezaki, H., Kusaba, M., and Yaegashi, H. 2002. Relationship between avirulence genes of the same family in rice blast fungus Magnaporthe grisea. J. Gen. Plant Pathol. 68:300-306.
Malandrakis, A., Markoglou, A., and Ziogas, B. 2011. Molecular characterization of benzimidazole-resistant $B$. cinerea field isolates with reduced or enhanced sensitivity to zoxamide and diethofencarb. Pestic. Biochem. Physiol. 99:118-124.

Masner, P., Muster, P., and Schmid, J. 1994. Possible methionine biosynthesis inhibition by pyrimidinamine fungicides. Pestic. Sci. 42:163-166.

Milling, R. J., and Richardson, C. J. 1995. Mode of action of the anilinopyrimidine fungicide pyrimethanil. 2. Effects on enzyme secretion in Botrytis cinerea. Pestic. Sci. 45:43-48.

Pillonel, C., and Meyer, T. 1997. Effect of phenylpyrroles on glycerol accumulation and protein kinase activity of Neurospora crassa. Pestic. Sci. 49:229-236.

Sun, H.-Y., Wang, H.-C., Chen, Y., Li, H.-X., Chen, C.-J., and Zhou, M.-G. 2010 Multiple resistance of Botrytis cinerea from vegetable crops to carbendazim, diethofencarb, procymidone, and pyrimethanil in China. Plant Dis. 94:551-556.

Triphati, R. K., and Schlosser, E. 1982. The mechanism of resistance of B. cinerea to methyl benzimidazol-2-yl-carbamate (MBC). J. Plant Dis. Prot. 89:151-156.

Vermeulen, T., Schoonbeek, H., and De Waard, M. A. 2001. The ABC transporter BcatrB from Botrytis cinerea is a determinant of the activity of the phenylpyrrole fungicide fludioxonil. Pest Manage. Sci. 57:393-402.

Walker, A.-S., Micoud, A., Rémuson, F., Grosman, J., Gredt, M., and Leroux, P. 2013. French vineyards provide information that opens ways for effective resistance management of Botrytis cinerea (grey mould). Pest Manage. Sci. 69:667-678.

Wang, J.-X., Ma, H.-X., Chen, Y., Zhu, X.-F., Yu, W.-Y., Tang, Z.-H., Chen, C.-J., and Zhou, M.-G. 2009. Sensitivity of Sclerotinia sclerotiorum from oilseed crops to boscalid in Jiangsu Province of China. Crop Prot. 28:882-886.

Weber, R. W. S. 2011. Resistance of Botrytis cinerea to multiple fungicides in northern German small-fruit production. Plant Dis. 95:1263-1269.

Yarden, O., and Katan, T. 1993. Mutations leading to substitutions at amino acids 198 and 200 of beta-tubulin that correlate with benomyl-resistance phenotypes of field strains of Botrytis cinerea. Phytopathology 83:1478-1483.

Yin, Y. N., Kim, Y. K., and Xiao, C. L. 2011. Molecular characterization of boscalid resistance in field isolates of Botrytis cinerea from apple. Phytopathology 101:986-995.

Zhang, C.-q., Hu, J.-1., Wei, F.-1., and Zhu, G.-n. 2009a. Evolution of resistance to different classes of fungicides in Botrytis cinerea from greenhouse vegetables in eastern China. Phytoparasitica 37:351-359.

Zhang, C. Q., Liu, Y. H., and Zhu, G. N. 2009b. Detection and characterization of benzimidazole resistance of Botrytis cinerea in greenhouse vegetables. Eur. J. Plant Pathol. 126:509-515.

Zhang, C. Q., Yuan, S. K., Sun, H. Y., Qi, Z. Q., Zhou, M. G., and Zhu, G. N. 2007. Sensitivity of Botrytis cinerea from vegetable greenhouses to boscalid. Plant Pathol. 56:646-653.

Ziogas, B. N., and Girgis, S. M. 1993. Cross-resistance relationships between benzimidazole fungicides and diethofencarb in Botrytis cinerea and their genetical basis in Ustilago maydis. Pestic. Sci. 39:199-205. 